\title{
Recognition of Emotional Facial Expressions in Alexithymia
}

\author{
Francisco Martinez-Sanchez, Enrique G. Fernández-Abascal, Noelia Sánchez-Pérez \\ Universidad de Murcia, Murcia, Spain
}

\begin{abstract}
Alexithymia is a personality trait which is associated with difficulties in identifying and verbalizing emotions. Previous studies have shown a significant association between alexithymia and a lack of ability to decode emotional facial expressions. Three groups of university students $(N=1645)$ were formed by splitting the sample based on Toronto Alexithymia Scale (TAS-20) scores. All participants performed an emotional expression recognition task, using the "Reading the Mind in the Eyes" method. The experimenter presented images of the eye-region of the faces of actors and actresses. As expected, results showed that alexithymics performed worse on ability to infer others' emotional states expressed by the eyes. These results suggest that alexithymia is associated with impaired emotion recognition, that is most apparent when processing capacity is restricted, high-alexithymic individuals could develop less detailed perceptual representations of facial expression which might impair the process of drawing conclusions about its emotional significance.
\end{abstract}

Key words: alexithymia, eyes expression, recognition, emotion, Eyes Test

The term Alexithymia (from Greek: lack of words for emotions), refers to a specific disturbance in affective-emotional processing that is manifested through the following salient features: 1) difficulty in identifying and describing feelings and emotions verbally, 2) difficulty in distinguishing between feelings and somatic sensations that accompany emotional arousal, and 3) externally-oriented thinking and impaired symbolic activity (Taylor \& Bagby, 2004). The most recent research has stressed the point that in alexithymia there is not only a difficulty in expressing emotions verbally but also a deficit in the cognitive processing of emotions (Berenbaum \& Prince, 1994; Jessimer \& Markham, 1997; Lundh \& Simonsson-Sarnecki, 2002; Parker, Taylor, \& Bagby, 1993; Roedema \& Simons, 1999; Suslow, 1998; Suslow \&

Correspondence concerning this article should be addressed to Francisco Martinez-Sanchez, Ph.D., Facultad de Psicología, Universidad de Murcia, Murcia, Spain, E-mail: franms@um.es

Received November 11, 2016
Junghanns, 2002); as a consequence, emotions remain undifferentiated and poorly regulated (Taylor, Bagby, \& Parker, 1991) and those afflicted are more likely to misinterpret their emotions as being symptoms of illness (Taylor \& Bagby, 2004).

First studied in classical psychosomatic or somatic disorders, alexithymia is known today as a personality trait (Martínez-Sánchez, Ato, Córcoles, Huedo, \& Selva, 1998; MartínezSánchez, Ato, \& Ortiz, 2003), normally distributed in the general population with significantly higher levels in male subjects (Franz et al., 2008; Schimmenti, 2016). A high level of alexithymia is considered as a possible vulnerability factor for a variety of psychiatric disorders and physical illnesses (Taylor, Bagby, \& Parker, 1997), such as substance use disorders, somatization, anxiety and depression, and even schizophrenia (Lumley, Neely, \& Burger, 2007).

Alexithymics appear to be less able to recognize their emotion signals and regulate emotions effectively (Taylor et al., 1997). Several studies demonstrated that alexithymic individuals are 
impaired in their ability to recognize emotion when both the stimulus and the response are non-verbal, suggesting that alexithymia, "the lack of words for emotion", is not just a verbal phenomenon. Several authors hypothesized that hampered regulation of emotion in alexithymia might be based on deficits in the perception and further processing of emotional stimuli (Aleman, 2005; Martínez-Sánchez, Montero, \& de la Cerra, 2002; Lane, Sechrest, Reidel, Shapiro, \& Kaszniak, 2000). This statement has been empirically supported by imaging data (Kano et al., 2003; Mantani, Okamoto, Shirao, Okada, \& Yamawaki, 2005; Moriguchi et al., 2006) and event-related potentials (Pollatos \& Gramann, 2011).

One of the most fruitful areas of investigation that has occupied the investigation of alexithymia is the study of the patterns of recognition of facial expressions of emotion. It is well established that facial emotion recognition has an important place in emotion regulation, interpersonal communication skills, and in the development of psycho-pathologies (Öztürk, Kiliç, Deveci, \& Kirpinar, 2016).

In this line, previous studies have shown a significant correlation between alexithymia and a lack of ability to recognize emotions in photographs of facial expressions (Allerdings, 1997; Lane et al., 1996, 2000; Mann, Wise, Trinidad, \& Kohanski, 1994; McDonald \& Prkachin, 1990; Pandey \& Mandal, 1997; Parker et al., 1993; Parker, Prkachin, \& Prkachin, 2005; Prkachin, Casey, \& Prkachin, 2009). These deficits have been found with tasks in which participants were required to reply in a very short period of time (Pedrosa et al., 2009), as well as in those with masked stimuli to make it difficult to recognize them (Kugel et al., 2008; Reker et al., 2010), and with static emotional stimuli, such as FACS, and dynamic videos (Kätsyri, Saalasti, Tiippana, von Wendt, \& Sams, 2008; Ridout, Thomas, \& Wallis, 2010) (for a review, see Grynberg et al., 2012).
Despite the interest in studying the relationship between alexithymia and emotion recognition, there are only a few studies addressing the role of alexithymia in facial recognition tasks with parts of the face, such as the work of Swart, Kortekaas, and Aleman (2009) and Schimmenti (2016). This restricted condition is expected to make these recognition tasks considerably more difficult. Following this line, in the current study we aimed to examine how people with alexithymia are affected when they look at pictures of various facial expressions of the eye region, comparing the results with those without alexithymia. More specifically, we studied the response to a task that significantly hinders recognition, such as the "Reading the Mind in the Eyes" (Baron-Cohen, Wheelwright, Hill, Raste, \& Plumb, 2001), in which the subjects are presented a very small part of the face, restricted to the eye region. The "Reading the Mind in the Eyes" is widely used to assess individual differences in social cognition and emotion recognition across different groups and cultures, showing a sufficient internal consistency, adequate split-half and test-retest reliability, and good convergent validity (Fernández-Abascal, Cabello, FernándezBerrocal, \& Baron-Cohen, 2013; Schimmenti, 2016; Vellante et al., 2013; Yildirim, Kaşar, Güdük, Ateş, Küçükparlak, \& Ozalmete, 2011).

The nonverbal Eyes Test requires participants to make inferences about the affective and motivational state of others on the basis of a picture of their eyes. This task differs from identifying basic facial expressions of emotion in that the distinctions made involve more complex emotional terms and often concern social interaction (e.g., distinctions include attraction or repulsion, noticing you or ignoring you). In this study, we aimed to evaluate the effect of the presentation of expressions restricted to one specific part of the face on recognition rates in subjects with different levels of alexithymia. The null hypothesis was that the recognition 
rates of facial expressions would be independent of levels of alexithymia.

\section{Method}

\section{Participants}

Participants $(N=1645)$ consisted of 430 men and 1215 women, ranging in age from 18 to 50 $(M=31.31 ; S D=9.72)$ participated in this experiment, recruited from sections of a course in General Psychology at a large public Spanish University. All students were informed that their participation was entirely voluntary and, upon completing the informed consent process, all participants completed a battery of measures. We explained to them that we were studying the recognition of emotional facial expressions.

Confidentiality was described by informing participants that their responses would not be connected to identifying information in any way. Identifying information was not collected for any other purpose. The data was collected during three academic years, from 2012 to 2015.

\section{Materials and Measures}

The Toronto Alexithymia Scale (TAS-20; Bagby, Parker, \& Taylor, 1994), Spanish version (Martínez-Sánchez, 1996), was used to measure the participants' alexithymic level. The TAS-20 is a 20-item self-report measure of the alexithymic construct with good internal consistency, high test-retest reliability and construct and criterion validity (Bagby, Taylor, \& Parker, 1994; Paéz et al., 1999; Taylor, Bagby, \& Luminet, 2000). A three-factor structure is theoretically congruent with the alexithymia construct: (F. 1.) difficulty to identify feelings and to distinguish between feelings and somatic sensations of emotional arousal; (F. 2.) difficulty in describing feelings to others; and (F. 3.) externally-oriented thinking. A Spanish version of TAS-20 was accomplished by Spanish psychologists fluent in both English and Spanish, using backtranslation methodology. This version showed good internal consistency, $\alpha=.78$, and testretest reliability, $r=.71, p<.001$, over a 19-week interval. These results are comparable to those obtained with the English version of the scale. For this study, Cronbach's $\alpha$ for the TAS-20 sum score was .87 , for the scale difficulties identifying feelings .86 , for the scale difficulties describing feelings, and .71 for the scale externally-oriented thinking.

Computerized version of the 'Reading the Mind from the Eyes'. In this study, we used the revised version of the Eyes Test (BaronCohen et al., 2001), which involves inferring the mental state of a person from just the information conveyed in photographs of that person's eyes. The task consists of 36 black and white photographs $(15 \times 6 \mathrm{~cm})$ of the eye region; from just above the eyebrows to halfway down the bridge of the nose, presented along with 4 complex mental state words (e.g., jealous, panicked, arrogant and hateful). Each photograph has four options, which include one target word and three foils. The subjects are asked to choose the option, which best describes what the eyes in the photograph think or feel. Half of the photos depict females and half depict males, and all involve complex cognitive and emotional states. Scoring consisted of tallying the number of correct responses. Further details on the Eyes Test are presented in Baron-Cohen et al. (2001).

\section{Procedure}

The study was approved by the university institutional review board and all participants provided fully informed consent. After a description of the study, participants were given the demographic questionnaire and the TAS20 and they completed the experimental tasks in a laboratory during a single session. The participants were not timed. 
The Eyes Test task was presented on a laptop computer screen. The photograph was centered on the screen, and the four-target word was placed at the four corners of the photograph equally spaced from the center of the screen. Participants responded by pressing one of four keys on the keyboard (i.e., S, X, K, M) identified by colored stickers. These keys were chosen because they are spatially analogous to the location of the adjectives at the corners of the screen.

Scores are calculated as the total number of correct discriminations for all 36 items. We also classified the stimuli used in the Eyes task into three emotional valence categories: positive (8 items), neutral (16 items) and negative (12 items), using the criterion of Yildirim et al. (2011) and Fertuck et al. (2009).

\section{Statistical Analysis}

First, we used previously established cutoff scores on the TAS-20 to assign subjects to alexithymia groups (Bagby et al., 1994). The cutoff scores were as follows: nonalexithymic $(\leq 51)$, probable $(\geq 52-60 \leq)$ and alexithymic $(\geq$ $61)$. Second step was to compute zero-order correlations between TAS scores and emotional valence of stimuli used in the Eyes task. Third, a $3 \times 2$ factorial analysis of variance (ANOVA) was run to assess the potential differences in the total number of expressions recognized according to two factors: alexithymia group and gender. Lastly, another ANOVA was run to analyze the alexithymia group and gender effects on the different eyes expressions recognized.

\section{Results}

Table 1 shows the accuracy rates on the emotion recognition tasks as a function of alexithymia groups and gender.

Zero-order correlations revealed that alexithymia was significantly negatively correlated with the global precision of participants' recognition $(r=-.092, p<.01)$, of negative $(r=-.055$, $p<.05)$ and neutral eyes $(r=-.109, p<.01)$, however, was not significantly correlated with positives eyes $(r=-.012, p>.05)$.

A $3 \times 2$ factorial analysis of variance (ANOVA) was performed, to assess the potential differences in the total number of expressions recognized according to two factors: alexithymia group (Alexithymic - Probable- Nonalexithymic) and gender (male - female). The means and standard deviations of the two factors are presented in Table 1. The results for the ANOVA indicated a significant effect for alexithymia group factor,

Table 1 Performance accuracy on eyes recognition task

\begin{tabular}{lrcccc}
\hline \multicolumn{5}{c}{ Correct responses } \\
\hline Group & \multicolumn{1}{c}{$n$} & Total $(S D)$ & Positives $(S D)$ & Neutral $(S D)$ & Negatives $(S D)$ \\
\hline Nonalexithymic & 1398 & $26.79(3.37)$ & $5.96(1.39)$ & $12.11(1.90)$ & $8.71(1.65)$ \\
Males & 358 & $26.43(3.44)$ & $5.94(1.42)$ & $11.98(1.91)$ & $8.49(1.71)$ \\
Females & 1031 & $26.92(3.34)$ & $5.97(1.39)$ & $12.15(1.90)$ & $8.79(1.63)$ \\
Probable & 158 & $25.94(3.78)$ & $5.95(1.46)$ & $11.59(1.90)$ & $8.39(1.80)$ \\
Males & 43 & $25.24(4.40)$ & $5.97(1.58)$ & $11.53(2.32)$ & $7.90(1.71)$ \\
Females & 115 & $26.20(3.51)$ & $6.01(1.42)$ & $11.61(1.89)$ & $8.57(1.67)$ \\
Alexithymic & 98 & $25.60(4.12)$ & $5.87(1.45)$ & $11.38(2.21)$ & $8.33(1.81)$ \\
Males & 29 & $24.79(4.48)$ & $5.82(1.62)$ & $10.79(1.93)$ & $8.17(2.07)$ \\
Females & 69 & $25.94(3.94)$ & $5.89(1.39)$ & $11.63(2.28)$ & $8.40(1.70)$ \\
\hline
\end{tabular}


Table 2 Correlations between TAS-20 scores and the number of correctly recognized expressions

\begin{tabular}{lllll}
\hline & \multicolumn{4}{c}{ Correct responses } \\
\cline { 2 - 5 } & Total & Positive & Neutral & Negative \\
\hline DIF & $-.05^{*}$ & -.03 & $-.07^{* *}$ & -.01 \\
DDF & $-.06^{*}$ & -.01 & $-.08^{* *}$ & -.02 \\
EOT & $-.12^{* *}$ & .03 & $-.12^{* *}$ & $-.12^{* *}$ \\
TAS Total & $-.09^{* *}$ & -.01 & $-.11^{* *}$ & $-.06^{*}$ \\
\hline
\end{tabular}

Note. DIF: difficulties in identifying feelings; DDF: difficulties in describing feelings; EOT: externally-oriented thinking style.

$* p<.05 ; * * p<.01 ; * * * p<.001$

$F(2,1389)=8.96 ; p<.001 ; \eta p^{2}=.011$, and a significant effect for gender, $F(1,1389)=6.794$, $p<.01 ; \eta p^{2}=.004$, but non-significant interaction between both factors was found, $F(2,1389)$ $=0.570 ; p=.565 ; \eta p^{2}=.001$. The post-hoc comparisons with a Bonferroni adjustment revealed significant mean-differences effects between the groups of "nonalexithymic" and "alexithymic" $\left(M_{\text {NonAlex }}=26.79, S D=3.37 ; M_{\text {Alex }}=25.60\right.$, $S D=4.12)(d=1.19, p<.01)$, and between "nonalexithymic" and "probable" $\left(M_{\text {ProbAlex }}=\right.$
25.94, $S D=3.78)(d=.85, p<.01)$, but not among subjects in the "probable" and "alexithymic" $(d=.34, \mathrm{~ns})$.

We then classified the stimuli presented in response to the hedonic valence (positive, neutral or negative) of the expressions shown, in order to assess whether the level of alexithymia and gender was related to the differential recognition of one or another type of expression. No effect was found in any of the positive eyes recognition $\left(F(2,1389)=.252, p=.777 ; \eta p^{2}=\right.$

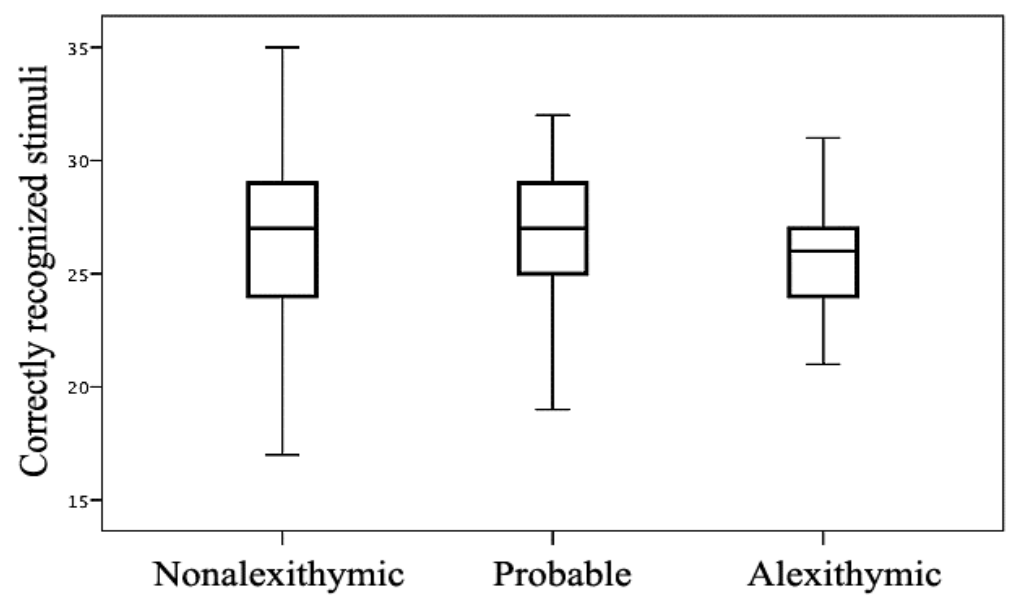

Figure 1 Mean of correctly recognized stimuli for the three alexithymia groups 


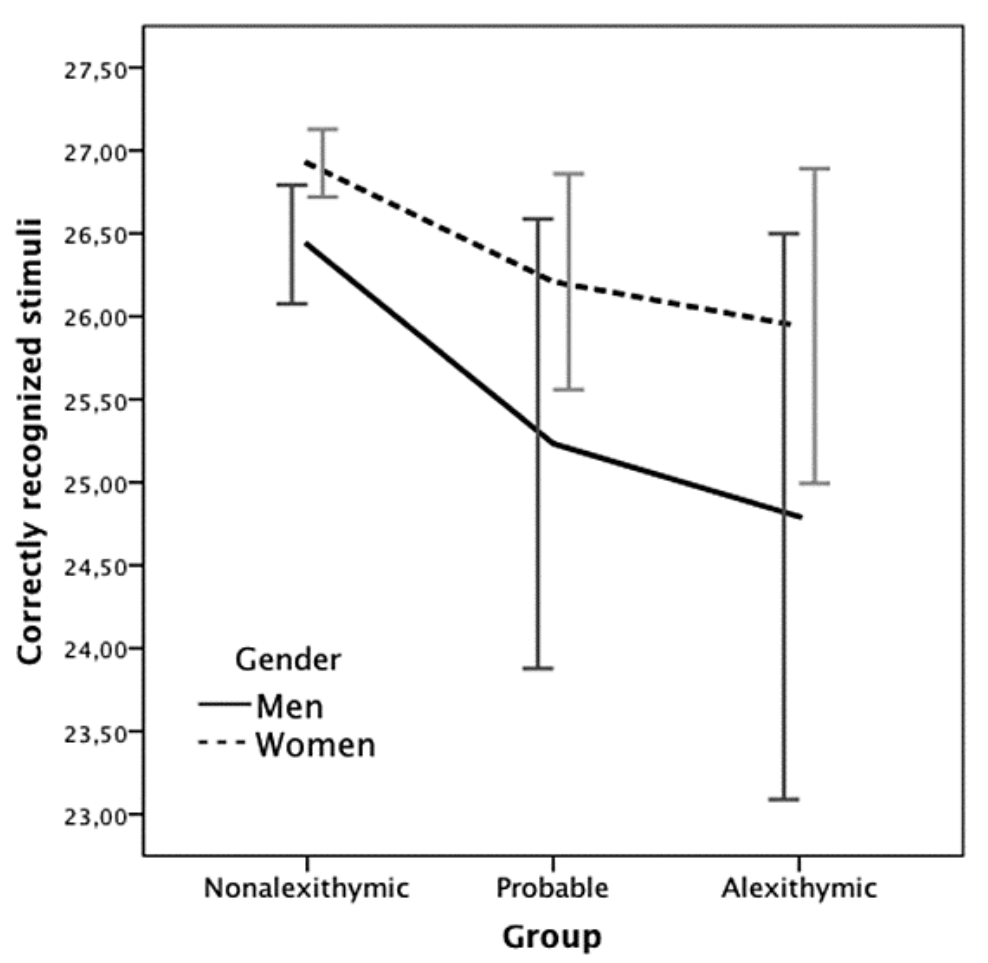

Error Bars: $95 \% \mathrm{Cl}$

Figure 2 Mean of correctly recognized stimuli for the three alexithymia groups and gender

.000) related to alexithymia group, but there was a significant effect for the response to the neutral $\left(F(2,1389)=10.279, p<.001 ; \eta p^{2}=.012\right)$ and negative eyes $(F(2,1389)=4.602, p<.05$; $\left.\eta p^{2}=.004\right)$. A significant effect was also found for gender in negatives eyes, $F(1,1389)=6.040$, $p<.05 ; \eta p^{2}=.004$, but no for positive $\left(F(2,1389)=0.632, p=.427 ; \eta p^{2}=.000\right)$ or neutral eyes $\left(F(2,1389)=3.671, p=.055 ; \eta p^{2}=\right.$ $.004)$. The interaction of the factors "alexithymia group" and "gender" yielded a non-significant interaction in recognition of any type of expression. Follow-up post-hoc tests with a Bonferroni adjustment were conducted to evaluate the group differences among the means for alexithymia group in negative and neutral eyes independently. In the case of negative eyes, the "nonalexithymic" group $\left(M_{\text {NonAlex }}=8.71\right.$, $S D=1.65)$ was marginally more accurate than the "alexithymic" $\left(M_{\mathrm{Alex}}=8.33, S D=1.81\right)$ and the "probable" $\left(M_{\text {ProbAlex }}=8.39, S D=1.80\right)$ alexithymia group $(d=-.38, p=.092$, and $d=$ $-.32, p=.065$, respectively). In the condition of neutral eyes, the "nonalexithymic" group $\left(M_{\text {NonAlex }}=12.11, S D=1.90\right)$ showed significantly higher accuracy on recognition task than "probable" $\left(M_{\text {ProbAlex }}=11.59, S D=1.90\right)(d=$ $.518, p<.01)$ and "alexithymic" groups $\left(M_{\text {High }}=\right.$ $11.38, S D=2.21)(d=.725, p<.01)$, but not among subjects in the "probable" and "high alexithymia" group ( $d=.207$, ns). Finally, independent $t$-test yielded a significant result, 
$t(-3.41), p=.001$ with females scoring higher in negative eyes condition $(M=8.75, S D=1.64)$ than males $(M=8.42, S D=1.79)$.

\section{Discussion}

In the present study, emotional recognition of facial expressions of the eye region was investigated as a function of alexithymia as measured by the TAS-20 in a large sample. The main results show that alexithymia is associated with a decreased ability to recognize facial emotional information type, especially the negative hedonic valence; on the other hand, women have shown to be more capable at recognizing expressions than men.

Our findings indicate that alexithymia is associated with a deficit in the recognition of emotional expressions within restricted conditions, that is, when the stimulus shown is the eye region exclusively. This is consistent with the work of Parker et al. (2005), in which the authors found difficulties in identifying facial expressions when participants had limited time to complete the task. These results suggest that alexithymia is related to a poor recognition of facial expressions when stimuli are presented under suboptimal conditions (i.e., when the stimuli were spatially degraded or briefly presented above the threshold of conscious detection during experimental conditions, Parker, Prkachin, \& Prkachin, 2005; Prkachin, Casey, \& Prkachin, 2009).

The ability to accurately detect emotional facial expressions is a necessary condition to make adjustments and personal reactions, such as the running of emotional self-regulatory processes. Our pattern of results represents a basis for explaining the difficulties of personal relationships for alexithymics, justified by the difficulty in perceiving negative emotions in others, leading to difficulties in handling these situations adaptively, and the consequences that may entail. These limited empathic skills with high levels of alexithymia have been highlighted in several studies (Bird, Silani, Brindley, White, Frith, \& Singer, 2010; Grynberg, Luminet, Cornelius, Greg, \& Berthoz, 2010; Moriguchi et al., 2007).

Our results are consistent with previous studies in which authors have presented images of facial expressions taken from FACS (Allerdings, 1997; Lane et al., 1996, 2000; McDonald \& Prkachin, 1990; Mann et al., 1994; Pandey \& Mandal, 1997; Parker et al., 2005; Prkachin et al., 2009; Reker et al., 2010), as well as those who have had facial micro-expressions (Swart, Kortekeer, \& German, 2009), and degraded presentations of facial expressions that hinder its recognition (Kätsyri et al., 2008). On the other hand, studies using the affective priming task (Suslow, 1998; Suslow \& Junghanns, 2001; Suslow et al., 2001) have showed inconsistent results. It could be explained by the fact that each of these studies used different procedures, although it has been observed that subjects with high levels of alexithymia seem to show difficulties in linking the emotional stimuli and the mental representation of emotional concepts. For example, Vermeulen, Luminet, and Corneille (2006) found that subjects with high levels of alexithymia showed reduced priming when presented with a prime consisting of facial expressions of anger, followed by a verbal target.

The task used in the present work was not time limited, like most of the studies already mentioned. However, results involving tasks with a very brief presentation of the stimuli have indicated that alexithymics are less skilled than non-alexithymics in judging facial expressions quickly (1 sec). Nonetheless, this difference does not exist in the presentations where the stimuli is longer ( $3 \mathrm{sec}$ ) (Parker et al., 2005) or when the subjects were asked to label the facial expressions without time limitations to perform the task (McDonald \& Prkachin, 1990). These results suggest that the greater the demand for recognition, the higher the recognition deficit 
will be, this is also true when verbal demands are high (Parker et al., 1993), or when verbal demands are very low with a short stimuli time. As an example, Prkachin et al. (2009) presented stimulus (facial expressions FACS) for $33 \mathrm{~ms}$ by using the signal detection paradigm, and the results showed marked difficulties in identifying emotional facial expressions, especially fear. Based on these findings, Grynberg et al. (2012) concluded that HAIs have problems labeling facial expressions, as they cannot process the perceptual information in a very short time.

But more interestingly, our findings indicate that alexithymics show greater difficulty in recognizing negative facial expressions. This pattern of results seems to confirm the existence of a difficulty in processing this type of emotions, in line with what has been previously demonstrated (Ihme et al., 2014; Parker et al., 1993; Parker et al., 2005; Prkachin et al., 2009). In this sense, Vanman, Dawson, and Brennan (1998) showed that the subjects with high levels of alexithymia valued negative images as less unpleasant than the subjects with low levels of alexithymia, or valued facial expressions of pain with lesser value than subjects with low levels of alexithymia (Moriguchi, Decety, Ohnishi, Maeda, Matsuda, \& Komaki, 2007).

Concerning the gender differences, we found that females scored higher than men on emotion recognition, specifically on neutral and negative stimuli. In this line, prior research has noted that women are more accurate than men in recognizing emotions under conditions of minimal stimulus information (Hall \& Matsumoto, 2004; Schimmenti, 2016), with subtle facial displays (Hoffman, Kessler, Eppel, Rukavina, \& Traue, 2010), and, specifically, labelling negative emotions, such as sadness (Montagne, Kessels, Frigerio, de Haan, \& Perrett, 2005). Our findings add empirical support to gender differences in the recognition of negative emotions under suboptimal conditions.
A number of limitations related to the current study should be noted. First, we did not evaluate participants' emotional state, neither their socioeconomic status nor their IQ, and these variables have been confirmed to influence on levels of alexithymia, anxiety and depression (Kirmayer \& Robbins, 1993; Öztürk et al., 2016; Wise et al., 1990). The only study controlling for verbal abilities found no significant differences in facial emotion recognition between healthy subjects relatively high or low in alexithymia (Montebarocci, Surcinelli, Rossi, \& Baldaro, 2011). However, our wide sample includes participants of a relatively homogeneous socioeconomic status (mostly undergraduates from a middle-socioeconomic status), might compensate for this limitation. Second, alexithymia was measured by self-report and, even if our questionnaire, TAS-20, has proved to be an acceptable and reliable instrument to the assessment of alexithymia, future research should include other measures to study the generalization and validity across measurements. For instance, the Toronto Structured Interview for Alexithymia (Bagby, Taylor, Parker, \& Dickens, 1996) would provide essential information about the relation between levels of alexithymia and the recognition of emotional stimuli. Finally, it should be emphasized that the present findings were obtained with a sample of healthy undergraduates, indeed, one might expect that greater differences would be observed were a clinical sample to be employed.

In summary, our results showed that facial recognition accuracy was negatively correlated with the alexithymia score, suggesting that alexithymics performed worse on emotion recognition when processing capacity is restricted. High-alexithymic individuals could develop less detailed perceptual representations of facial expression, which might impair the process of drawing conclusions about its emotional significance. These findings indicate that alexithymia is associated with an impaired recogni- 
tion of emotion, which may be a marker of a more general impairment in the capacity for emotion information processing. It still remains to be determined whether the deficit is at an evaluative level, as proposed by Berthoz et al. (2002), and whether or not the perceptual aspects of processing are affected.

\section{References}

Aleman, A. (2005). Feelings you can't imagine: Towards a cognitive neuroscience of alexithymia. Trends in Cognitive Sciences, 9(12), 553-555.

Allerdings, M. D. (1997). The identification of facial emotion: Do alexithymia and mood play a role? Saskatchewan Psychologist, 24, 4-5.

Bagby, R. M., Parker, J. D., \& Taylor, G. J. (1994). The twenty-item Toronto Alexithymia Scale-I. Item selection and cross-validation of the factor structure. Journal of Psychosomatic Research, 38(1), 2332

Bagby, R. M., Taylor, G. J., \& Parker, J. D. (1994). The twenty-item Toronto Alexithymia Scale-II. Convergent, discriminant, and concurrent validity. Journal of Psychosomatic Research, 38(1), 33-40.

Bagby, R. M., Taylor, G. J., Parker, J. D. A., \& Dickens, S. (1996). The development of the Toronto Structured Interview for Alexithymia: Item selection, factor structure, reliability and concurrent validity. Psychotherapy and Psychosomatics, 75, 25-39.

Baron-Cohen, S., Wheelwright, S., Hill, J., Raste, Y., \& Plumb, I. (2001). The 'reading the mind in the eyes' test revised version: A study with normal adults, and adults with Asperger syndrome or high-functioning autism. Journal of Child Psychology and Psychiatry, 42(2), 241-251.

Berenbaum, H., \& Prince, J. D. (1994). Alexithymia and the interpretation of emotion-relevant information. Emotion and Cognition, 8(3), 231-244.

Berthoz, S., Artiges, E., Van de Moortele, P. F., Poline, J. B., Rouquette, S., Consoli, S. M., \& Martinot, J. L. (2002). Effect of impaired recognition and expression of emotions on frontocingulate cortices: An fMRI study of men with alexithymia. American Journal of Psychiatry, 159(6), 961-967.

Bird, G., Silani, G., Brindley, R., White, S., Frith, U., \& Singer, T. (2010). Empathic brain responses in insula are modulated by levels of alexithymia but not autism. Brain, 133(5), 1515-1525.

Duchesneau, A. (1996). Alexithymia and visual perception. Perceptual Motor Skills, 83, 291-298.

Fernández-Abascal, E. G., Cabello, R., FernándezBerrocal, P., \& Baron-Cohen, S. (2013). Test-retest reliability of the 'Reading the Mind in the Eyes' test: A one-year follow-up study. Molecular Autism, 4(33), 1-6.

Fertuck, E. A., Jekal, A., Song, I., Wyman, B., Morris, M. C., Wilson, S. T., Brodsky, B. S. \& Stanley, B. (2009). Enhanced 'Reading the Mind in the Eyes' in borderline personality disorder compared to healthy controls. Psychological Medicine, 39(12), 19791988.

Franz, M., Popp, K., Schaefer, R., Sitte, W., Schneider, C., Hardt, J...,. \& Braehler, E. (2008). Alexithymia in the German general population. Social Psychiatry and Psychiatric Epidemiology, 43(1), 54-62.

Grynberg, D., Luminet, O., Corneille, O., Grčzes, J., \& Berthoz, S. (2010). Alexithymia in the interpersonal domain: A general deficit of empathy? Personality and Individual Differences, 49(8), 845-850.

Grynberg, D., Chang, B., Corneille, O., Maurage, P., Vermeulen, N., Berthoz, S., \& Luminet, O. (2012). Alexithymia and the processing of Emotional Facial Expressions (EFEs): Systematic review, unanswered questions and further perspectives. PLoS One, 7(8), e42429.

Hall, J. A., \& Matsumoto, D. (2004). Gender differences in judgments of multiple emotions from facial expressions. Emotion, 4(2), 201-206.

Hoffmann, H., Kessler, H., Eppel, T., Rukavina, S., \& Traue, H. C. (2010). Expression intensity, gender and facial emotion recognition: Women recognize only subtle facial emotions better than men. Acta Psychologica, 135(3), 278-283.

Ihme, K., Sacher, J., Lichev, V., Rosenberg, N., Kugel, H., Rufer, M., ... \& Suslow, T. (2014). Alexithymia and the labeling of facial emotions: Response slowing and increased motor and somatosensory processing. BMC Neuroscience, 15, 40.

Jessimer, M., \& Markham, R. (1997). Alexithymia: A right hemisphere dysfunction specific to recognition of certain facial expressions? Brain and Cognition, 34(2), 246-258.

Kano, M., Fukudo, S., Gyoba, J., Kamachi, M., Tagawa, M., Mochizuki, H., Itoh, M., Hongo, M., \& Yanai, K. (2003). Specific brain processing of facial expressions in people with alexithymia: An H215OPET study. Brain, 126(6), 1474-1484.

Kätsyri, J., Saalasti, S., Tiippana, K., von Wendt, L., \& Sams, M. (2008). Impaired recognition of facial emotions from low-spatial frequencies in Asperger syndrome. Neuropsychologia, 46(7), 1888-1897.

Kirmayer, L. J., \& Robbins, J. M. (1993). Cognitive and social correlates of the Toronto Alexithymia Scale. Psychosomatics, 34, 41-52.

Kugel, H., Eichmann, M., Dannlowski, U., Ohrmann, P., Bauer, J., Arolt, V., Heindel, W., \& Suslow T. (2008). Alexithymic features and automatic 
amygdala reactivity to facial emotion. Neurosciences Letter, 435(1), 40-44.

Lane, R. D., Sechrest, L., Reidel, R., Shapiro, D. E., \& Kaszniak, A. (2000). Pervasive emotion recognition deficit common to alexithymia and the repressive coping style. Psychosomatic Medicine, 62(4), 492-501.

Lane, R. D., Sechrest, L., Reidel, R., Weldon, V., Kaszniak, A. W., \& Schwartz, G. E. (1996). Impaired verbal and nonverbal emotion recognition in alexithymia. Psychosomatic Medicine, 58(3), 203 210.

Lumley, M. A., Neely, L. C., \& Burger, A. J. (2007). Assessing alexithymia in the medical setting: Implications for understanding and treating health problems. Journal of Personality Assessment, 89(1), 117. http://dx.doi.org/10.1080/00223890701629698

Lundh, L. G., \& Simonsson-Sarnecki, M. (2002). Alexithymia and cognitive bias for emotional information. Personality and Individual Differences, 32, 1063-1075.

Mann, L. S., Wise, T. N., Trinidad, A., \& Kohanski, R. (1994). Alexithymia, affect recognition, and the 5factor Model of Personality in normal subjects. Psychological Reports, 74(2), 563-567.

Mantani, T., Okamoto, Y., Shirao, N., Okada, G., \& Yamawaki, S. (2005). Reduced activation of posterior cingulate cortex during imagery in subjects with high degrees of alexithymia: A functional magnetic resonance imaging study. Biological Psychiatry 57(9), 982-990.

Martínez-Sánchez, F. (1996). The Spanish version of the Toronto Alexithymia Scale (TAS-20) [Adaptación espańola de la Escala de Alexitimia de Toronto (TAS-20)]. Clínica y Salud, 7(1), 19-32.

Martínez-Sánchez, F., Montero, J. M., \& de la Cerra, J. (2002). Cognitive biases in the recognition of synthetic emotional speech in alexithymia. [Sesgos cognitivos en el reconocimiento de expresiones emocionales de voz sinteětica en la alexitimia]. Psicothema, 14(2), 344-349.

Martínez-Sánchez, F., Ato, M., \& Ortiz, B. (2003). Alexithymia - state or trait? The Spanish Journal of Psychology, 6(1), 51-59.

Martínez-Sánchez, F., Ato, M., Coìrcoles, E., Huedo, T., \& Selva, J. (1998). Stability in the alexitimia levels: A longitudinal analysis of temporary series on various emotional answers. Personality and Individual Differences, 24(6), 767-772.

McDonald, P. W., \& Prkachin, K. W. (1990). The expression and perception of facial emotion in alexithymia: A pilot study. Psychosomatic Medicine, 52(2), 199-210.

Montebarocci, O., Surcinelli, P., Rossi, N., \& Baldaro, B. (2011). Alexithymia, verbal ability and emo- tion recognition. Psychiatric Quarterly, 82, 245252 .

Montagne, B., Kessels, R. P., Frigerio, E., de Haan, E. H., \& Perrett, D. I. (2005). Sex differences in the perception of affective facial expressions: Do men really lack emotional sensitivity?. Cognitive Processing, 6(2), 136-141.

Moriguchi, Y., Decety, J., Ohnishi, T., Maeda, M., Matsuda, H., \& Komaki, G. (2007). Empathy and judging other's pain: An fMRI study of alexithymia. Cerebral Cortex, 17(9), 2223-2234.

Moriguchi, Y., Ohnishi, T., Lane, R. D., Maeda, M., Mori, T., Nemoto, K., Matsuda, H., \& Komaki, G. (2006). Impaired self-awareness and theory of mind: An fMRI study of mentalizing in alexithymia. Neuroimage 32(3), 1472-1482.

Öztürk, A., Kiliç, A., Deveci, E., \& Kirpinar, I. (2016) Investigation of facial emotion recognition, alexithymia, and levels of anxiety and depression in patients with somatic symptoms and related disorders. Neuropsychiatric Disease and Treatment, 12, 1047-1053.

Páez, D., Martínez-Sánchez, F., Velasco, C., Mayordomo, S., Fernández, I., \& Blanco, A. (1999). Validez psicométrica de la Escala de Alexitimia de Toronto (TAS-20): Un estudio transcultural. Boletín de Psicología, 63, 55-76.

Pandey, R., \& Mandal, M. K. (1997). Processing of facial expressions of emotion and alexithymia. British Journal of Clinical Psychology, 36(4), 631-633.

Parker, J. D. A., Taylor, G. J., \& Bagby, R. M. (1993). Alexithymia and the recognition of facial expressions of emotion. Psychotherapy and Psychosomatics, 59(3-4), 197-202.

Parker, P. D., Prkachin, K. M., \& Prkachin, G. C. (2005). Processing of facial expressions of negative emotion in alexithymia: The influence of temporal constraint. Journal of Personality, 73(4), 1087-1107.

Pedrosa, F. P., Ridout, N., Kessler, H., Neuffer, M., Schoechlin, C., Traue, H. C., \& Nickel, M. (2009). Facial emotion recognition and alexithymia in adults with somatoform disorders. Depression and Anxiety, 26(1), 26-33. doi: 10.1002/da.20456

Pollatos, O., \& Gramann, K. (2011). Electrophysiological evidence of early processing deficits in alexithymia. Biological Psychology, 87(1), 113-121.

Prkachin, G. C., Casey, C., \& Prkachin, K. M. (2009). Alexithymia and perception of facial expressions of emotion. Personality and Individual Differences, 46(4), 412-417.

Reker, M., Ohrmann, P., Rauch, A. V., Kugel, H., Bauer, J., Dannlowski, U., Arolt, V., Heindel, W., \& Suslow, T. (2010). Individual differences in alexithymia and brain response to masked emotion faces. Cortex, 46(5), 658-667. 
Ridout, N., Thom, C., \& Wallis, D. J. (2010). Emotion recognition and alexithymia in females with nonclinical disordered eating. Eating Behaviors, 11(1), 1-5.

Roedema, T. M., \& Simons, R. F. (1999). Emotionprocessing deficit in alexithymia. Psychophysiology, 36(3), 379-387.

Schimmenti, A. (2017). The developmental roots of dissociation: A multiple mediation analysis. Psychoanalytic Psychology, 34(1), 96-105.

Suslow, T. (1998). Alexithymia and automatic affective processing. European Journal of Personality $12(6), 433-443$.

Suslow, T., \& Junghanns, K. (2002). Impairments of emotion situation priming in alexithymia. Personality and Individual Differences, 32(3), 541-550.

Suslow, T., Junghanns, K., Donges, U. S., \& Arolt, V. (2001). Alexithymia and automatic processing of verbal and facial affect stimuli. Cahiers de Psychologie Cognitive, 20(5), 297-324.

Swart, M., Kortekaas, R., \& Aleman, A. (2009). Dealing with feelings: Characterization of trait alexithymia on emotion regulation strategies and cognitive-emotional processing. Plos One, 4(6), e5751.

Taylor, G. J., \& Bagby, R. M. (2004). New trends in alexithymia research. Psychotherapy and Psychosomatics, 73(2), 68-77.

Taylor, G. J., Bagby, R. M., \& Parker, J. D. (1991) The alexithymia construct. A potential paradigm for psychosomatic medicine. Psychosomatics, 32(2), 153-164.

Taylor, G. J., Bagby, R. M., \& Parker, J. D. (1997) Disorders of affect regulation. Alexithymia in medi- cal and psychiatric illness. Cambridge: Cambridge University Press.

Taylor, G. J., Bagby, R. M., \& Luminet, O. (2000) Assessment of alexithymia: Self-report and observerrated measures. In R. Bar-On \& J. D. A. Parker (Eds.), The handbook of emotional intelligence (pp. 301319). San Francisco: Jossey-Bass.

Vanman, E. J., Dawson, M. E., \& Brennan, P. A (1998). Affective reactions in the blink of an eye: Individual differences in subjective experience and physiological responses to emotional stimuli. Personality and Social Psychology Bulletin, 24(9), 994-1005.

Vellante, M., Baron-Cohen, S., Melis, M., Marrone, M., Petretto, D. R., Masala, C., \& Preti, A. (2013). The "Reading the Mind in the Eyes" test: Systematic review of psychometric properties and a validation study in Italy. Cognitive Neuropsychiatry, 18(4), 326-354.

Vermeulen, N., Luminet, O., \& Corneille, O. (2006) Alexithymia and the automatic processing of affective information: Evidence from the Affective Priming Paradigm. Cognition and Emotion, 20(1), 6491 .

Wise, T. N., Mann, L. S., Mitchell, J. D., Hryvniak, M., \& Hill, B. (1990). Secondary alexithymia: An empirical validation. Comprehensive Psychiatry, 31, 284-288.

Yildirim, E. A., Kaşar, M., Güdük, M., Ateş, E., Küçükparlak, I., \& Ozalmete, E. O. (2011). Investigation of the reliability of the "Reading the Mind in the Eyes Test" in a Turkish population. Turkish Journal of Psychiatry, 22(3), 177-186. 